\title{
Cartas de amor desde la otra orilla. Análisis de las fuentes documentales para el estudio de las relaciones entre españolas y marroquíes durante la posguerra española
}

\author{
Nerea PÉREZ RUBIO \\ Universidad de Alcalá \\ nereape.nerea@gmail.com \\ Rocío MARIGIL ASENCIO \\ Universidad de Alcalá \\ rocio.marigil@gmail.com
}

Ana NASEIRO RAMUDO

Archivo General de la Administración. Departamento de Descripción y conservación ana.naseiro@mecd.es

Recibido: Febrero 2014

Aceptado: Abril 2014

Resumen: Este trabajo pretende dar luz a unos documentos conservados en el Archivo General de la Administración pertenecientes al fondo de África. El punto de partida es el estudio y tratamiento archivístico de un "fichero policial de vigilancia" y la serie de expedientes informativos a los que nos remite el fichero, generados por la Delegación de Asuntos Indígenas de la Alta Comisaría de España en Marruecos. Este estudio resulta de gran interés porque la Delegación de Asuntos Indígenas se encargó de la vigilancia y del control moral de la población española, judía, marroquí y extranjeros residentes o relacionados con el Protectorado. Para este trabajo se ha llevado a cabo tanto la ordenación y clasificación del fichero policial que sirvió de partida para la investigación, así como su digitalización en PARES. También el estudio de los expedientes a los que este fichero nos deriva. Es de resaltar la tipología diversa de documentos, incluyendo las cartas interceptadas que guardan en su interior verdaderas historias de amor y amistad, la mayoría de las veces rotas por "conveniencia" de una moral conservadora.

Palabras clave: Protectorado; Marruecos; Franquismo; Correspondencia; Censura; Vigilancia; Moral

Love letters from the other side.

Analysis of documentary sources for the study of the relationship between Spanish and Moroccan during the forties

Abstract: Our goal is to shed light on documents part of Africa's collection, preserved in the Archivo General de la Administración (General Archive of the Administration). The starting 
point is the study and archival management of a "police monitoring file" and a series of referenced records, generated by the Delegación de Asuntos Indígenas de la Alta Comisaría de España en Marruecos (Foreign Affairs Delegation of the Spanish High Moroccan Commission). The study is of great interest since the Delegación de Asuntos Indígenas was in charge of the morality enforcement over the Spanish, Jewish and Moroccan population as well as foreigners residing in or related to the Protectorate. This work comprises both the sorting and classification of the police file, which served as our starting point, as well as its digitization in PARES and the study of the records referenced by this file. The studied documents are noteworthy for their diverse typology, including intercepted mail, which reveals deep love and friendship often broken at the convenience of a conservative morality.

Keywords: Protectorate; Morocco; Francoism; Correspondence; Censorship; Surveillance; Moral

\section{INTRODUCCIÓN}

Quizá el caso más conocido de mujeres injustamente castigadas en la posguerra es el de las "Trece Rosas", nombre con el que se conoce a unas muchachas que fueron fusiladas por el régimen franquista el 5 de agosto de 1939, acusadas de cometer un delito que no pudieron ni presenciar ya que cuando se cometió ellas ya habían sido encarceladas. Sus edades estaban comprendidas entre los 18 y los 29 años.

Sin embargo, no debemos olvidar que hay muchas mujeres desconocidas que también sufrieron la persecución y el ostracismo del régimen por sus prácticas amorosas.

Nos encontramos con una temática que ha dado lugar a grandes "Best Sellers" como el de Dulce Chacón, que en su novela La Voz Dormida, nos muestra cómo tenían que vivir las mujeres en la madrileña cárcel de Ventas.

El objetivo de nuestro artículo es dar a conocer un capítulo más de la represión a la que fueron sometidas las mujeres en la posguerra, sólo por el hecho nacer mujer. Puesto que esta tarea se reserva a los investigadores, en este artículo se analizan las fuentes documentales que guardan la memoria de las relaciones prohibidas entre mujeres españolas y extranjeros, fundamentalmente marroquíes. Esta represión se manifestó en la correspondencia que fue interceptada o la prohibición de entrada en la zona del protectorado, entre otras manifestaciones; pero, no debemos olvidar que su único delito fue enamorarse. Buscaban el exotismo de África, intentando evadirse a otro mundo para así poder huir de la durísima realidad que las rodeaba, como hicieron en un pasado ya lejano los autores románticos. "Amar en tiempos revueltos" siempre ha sido complicado y aún más si deseas pasar el resto de tu vida con una persona extranjera.

El franquismo deseaba que todo estuviera en orden y que las mujeres cumplieran con las tareas del hogar y complacieran los deseos de sus maridos, otro punto importante en la vida conyugal fueron los hijos, ya que aseguraban la supervivencia de la especie. Si nos remitimos a la Guía de la buena esposa, podremos comprobarlo. 
Su autora fue Pilar Primo de Rivera, la creadora de la Sección Femenina quien curiosamente nunca contrajo matrimonio.

Algunas de las reglas para que las mujeres mantuvieran felices a sus maridos eran las siguientes:

- "Ten lista la cena."

- "Sé dulce e interesante."

- "Hazlo sentir en el paraíso."

- "Escúchalo."

- "No te quejes."

Las esposas siempre debían permanecer a la sombra de sus maridos y hacer todo lo que ellos les ordenaran. Si les contrariaban eran severamente castigadas. El represor realmente no era el marido, sino un régimen paternalista y retrógrado que se veía amenazado por todo lo que venía del extranjero, sobre todo, si suponía la liberación o progreso de la sociedad.

Este trabajo surgió mientras realizábamos las prácticas universitarias en el Archivo General de la Administración. El descubrimiento de las fichas de "la policía moral" nos llevó a la búsqueda de los expedientes a los que éstas se referían. Una vez encontrados los expedientes pudimos comprobar toda la tipología de documentación que éstos aportan y que describiremos más adelante. Tras una exhaustiva investigación tanto de las fichas como de los expedientes a los que hacen referencia iniciamos el proceso para facilitar la labor a los investigadores. Primero llevamos a cabo la ordenación de las fichas a la que siguió su digitalización en el sistema PARES, así como llevamos a cabo el proceso de descripción. Seguimos también con una breve investigación sobre el protectorado, así como las pautas y criterios que se ven reflejados en los expedientes para el seguimiento de individuos.

Es un trabajo interesante no solo por el contenido tanto de las fichas como de los expedientes, sino también por la diversa tipología documental que se encuentra referida en las fichas de las que partimos nuestra investigación.

\section{CONTEXTO HISTÓRICO}

La documentación analizada en esta investigación se circunscribe a un periodo convulso de nuestra historia, concretamente a la posguerra española.

Durante estos años una parte importante de la población tuvo que pagar las consecuencias derivadas de tres años de un conflicto armado que enfrentó en muchas ocasiones a personas de una misma familia, e incluso a vecinos. Como cualquier otra Guerra Civil causó una importante brecha entre compatriotas cuyas secuelas permanecerán presentes durante la vida de los que participaron en ella e incluso de sus descendientes. 
Cuando finalizó la Guerra Civil que se desarrolló entre los años 1936 y 1939 , en España había una gran pobreza y un malestar social, además de una fuerte represión, que sería constante durante todo el periodo franquista.

Se instauró una larga dictadura en cuyo primer periodo, que abarca desde el final de la guerra hasta los años cincuenta, se generó la documentación analizada en el presente artículo. Este primer periodo se caracterizó por una política interior desplegada por un régimen que nació tras la guerra; una autarquía económica en la que hubo grandes carencias y necesidades y un aislamiento al régimen de Franco por parte de las potencias vencedoras de la Segunda Guerra Mundial.

La documentación objeto de estudio se genera a raíz de las relaciones interpersonales entre españolas y marroquíes en este periodo de posguerra, por ello es interesante analizar los acontecimiento históricos de los que se derivaron dichas relaciones.

En 1912 se firmó el convenio franco-hispano, que dividiría Marruecos en dos áreas de protectorado, una francesa y otra española. Por este acuerdo los actos de las autoridades marroquíes serían intervenidos por el Alto Comisario y sus agentes, de modo que los actos del jalifa serían intervenidos directamente por el Alto Comisario y los del personal marroquí por los interventores. Entre los años 1913 y 1924, el Ministerio de Estado fue el primer organismo metropolitano encargado del protectorado, a través de la Dirección de Asuntos Marroquíes.

La ocupación del territorio marroquí no fue una tarea fácil para los contingentes españoles, para llevar a cabo un control efectivo, el territorio fue dividido en cinco regiones, denominadas Intervenciones: Rif, Yebala, GomaraXauen, Kert y Lucus, al frente de las cuales se situaron los interventores regionales, estos se encontraban bajo la dependencia directamente del Alto Comisario a través de la Delegación de Asuntos Indígenas. Por otro lado, las intervenciones se dividieron en cabilas, que estaban controladas por los interventores de cabila, que intervenían la actuación de los cadies (máximas autoridades marroquíes de las cabilas).

Tras la Guerra Civil, en base a la ley 8 de noviembre de 1941 se produjo una importante reorganización de la Alta Comisaría. Esta ley incrementó las funciones del Alto Comisario, pero supuso retomar un modelo militar de organización. Según la nueva organización, la Secretaría Diplomática, la Subinspección de Fuerzas Jalifianas, la Intervención de Marina y la Delegación de Asuntos Indígenas, se encontraban bajo las órdenes del Alto Comisario. La Delegación de Asuntos Indígenas (D.A.I.), que es el organismo encargado de generar la documentación estudiada en este artículo, asumió el papel más importante entre las delegaciones. Bajo su dependencia se encontraban los Servicios de Intervención Política, Información, Vigilancia y Seguridad. A pesar de la mayor importancia adquirida por la Delegación de Asuntos Indígenas, perdió funciones como los Servicios de Educación y Cultura, que pasaron a la Delegación de Educación y Cultura, y la Inspección de Higiene y Sanidad Pecuaria, que quedó integrada en la Delegación de Economía, Industria y Comercio. 
La Delegación de Asuntos Indígenas quedó compuesta por la Subdelegación, una Secretaría, la Sección Política, una Asesoría Jurídica Musulmana, la Comisaría de Seguridad y Orden Público y las Inspecciones de Entidades Municipales, de Sanidad y de la Mezjanía. Esta estructura no duró mucho y se creó una Sección de Cartografía, Prensa e Interpretación, y la Sección de Personal bajo dependencia del delegado. La Sección de Entidades Municipales y Rurales quedó bajo la dependencia del subdelegado. La Sección de Política e Intervención quedó bajo dependencia directa del delegado.

\subsection{LA DELEGACIÓN DE ASUNTOS INDÍGENAS}

A medida que fue creciendo la vida administrativa de la zona del protectorado se hizo necesaria la creación de un archivo que organizase la documentación de los diversos organismos oficiales. La Delegación de Asuntos Indígenas fue la primera entidad del Protectorado que intentó formar un archivo propio, debido tanto a sus importantes funciones como al gran volumen de documentación derivado de su cumplimiento. Este primer archivo se creó en 1934 para reunir los expedientes de las tropas de la Policía Indígena, Harka e Intervenciones Militares. Este centro se denominó Archivo General Jalifiano y estuvo organizado por personal de las oficinas militares.

Al propio tiempo fueron creciendo los archivos de las distintas Delegaciones, fue entonces cuando se hizo notoria la necesidad de crear un organismo encargado de reunir, organizar y conservar la documentación administrativa de la zona. Debido a ello, en 1945 nació el Archivo General del Protectorado que se incluyó en el servicio de Archivos y Bibliotecas del Protectorado, siendo instalado en locales de la Delegación de Educación y Cultura, aunque dependía administrativamente de la Delegación General de la Alta Comisaría. Fue en mayo de ese mismo año cuando fueron trasladados al local del nuevo archivo los fondos del antiguo Archivo Central Jalifiano, junto con otros muchos procedentes de las distintas Delegaciones y diversos servicios.

Como cualquier organismo del ámbito militar, la Delegación de Asuntos Indígenas, seguía la normativa de organización y clasificación de los archivos militares. En este ámbito la regulación de los archivos es temprana, ya la Real Orden de 17 de enero de 1752, establecía normas para la organización de esta tipología de archivos, aunque estuvieron largo tiempo en manos exclusivamente de gestores militares sin formación específica en archivística, concretamente hasta el Real Decreto del 14 de febrero de 1844 en el que se establecía personal especializado para la custodia y clasificación de los documentos. Los documentos que incluimos en este estudio se han generado por un organismo dirigido por personal militar y tiene un carácter reservado, por ello, vemos que su clasificación sigue la establecida en el Reglamento Archivos Militares de 1889, que estipulaba una organización basada en cinco secciones: Personal, Asuntos, Material, Causas y 
Reservado, que fue la primera clasificación normalizada para el conjunto de los archivos militares.

Al producirse la independencia política de Marruecos en el año 1956 se dispuso que se remitiese la documentación al Archivo-Biblioteca de la Dirección General de Plazas y Provincias Africanas, dependiente del Ministerio de la Presidencia, por referirse a actividades y personal español, debía de ser utilizado por la administración española y no por la marroquí. Esta documentación seleccionada por comisiones fue trasportada primero a Ceuta y luego a Madrid. Tras la evacuación de la última colonia africana, el Sahara, a finales de los setenta, se desmanteló el Archivo-Biblioteca de la Dirección General, siendo trasladada la totalidad de su documentación a la Sección de África del Archivo General de la Administración, lugar en el que hoy en día se ubica la parte de archivo.

Como hemos indicado, la Delegación de Asuntos Indígenas generó la documentación objeto de estudio, concretamente a través de las funciones que ejercía la Sección Segunda (Servicios de Intervención Política, Información, Vigilancia y Seguridad) del Negociado Segundo (Negociado de Información) que era el órgano que gestionaba la información que estaba en la base de una de las principales funciones de la Delegación de Asuntos Indígenas, la vigilancia del personal español, marroquí, judío y de otras procedencias.

La documentación se compone de un fichero informativo y referencial que remite a una serie de expedientes informativos relativos a correspondencia interceptada entre españolas y marroquíes ${ }^{1}$. El Negociado Segundo contaba con un conjunto de ficheros para la organización de la información, algunos de estos eran: el fichero de partidos políticos y cofradías en que figuren todos los afiliados; el fichero de personal maleante: contrabandistas, ladrones, confidentes de la otra zona...; el fichero de elementos aprovechables para fines políticos y militares,...

Estos ficheros se formaban según las instrucciones para el servicio de información en las cuales se detalla su conformación: "Del fichero General se tendrán hechos resúmenes numéricos del personal perteneciente a los distintos partidos políticos, sectas y cofradías.", "Todo individuo que destaque en alguna actividad deberá tener ficha". Estas instrucciones recogen los criterios que se seguían para recolectar la información que ha llegado a nuestras manos. Encontramos un gran interés por recopilar todo tipo de información y conservarla haciéndola accesible de forma rápida, segura y reservada, con la finalidad de llevar a cabo un control lo más exhaustivo posible de la población.

Entre los documentos que forman el expediente se dan indicaciones del proceso de su formación, tales como el traslado directo de las noticias concernientes a asuntos de otras oficinas del territorio, procediendo al propio tiempo a dar cuenta del asunto a la intervención territorial. Los informes de carácter urgente debían de

\footnotetext{
${ }^{1}$ Concretamente corresponde al tramo de signaturas de la caja: AGA, 81,2568 a la AGA, 81,2574 .
} 
ser directos del Interventor a la Delegación de Asuntos Indígenas, según indicaba el Delegado.

Las oficinas de las Intervenciones daban copias de los informes con carácter reservado a los Generales de circunscripción y a la Inspección General que era la encargada de remitir el resumen mensual de toda la zona al Alto Comisariado y al Cuartel General del Jefe Superior de las Fuerzas.

La información recopilada se configuraba en diferentes hojas de información de diferente periodicidad y tipología (diaria, resumen mensual de la situación, hoja de confidencias,...). La finalidad básica de este proceso era tener informado al Alto Comisario de todos los asuntos de la zona.

\section{TRATAMIENTO DOCUMENTAL Y ESTUDIO DIPLOMÁTICO}

El fichero del que parte este estudio fue localizado entre un conjunto de ficheros de este organismo que se encuentran sin tratamiento archivístico, concretamente, se trata del "Fichero policial de vigilancia de la conducta moral entre españolas y marroquíes de la Alta Comisaría de España en Marruecos"2. A partir de este fichero, se buscó la documentación referencial asociada al mismo en el sistema informático de descripción del Archivo General de la Administración

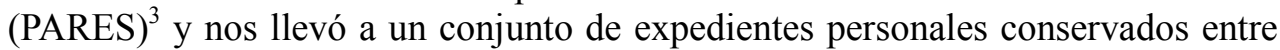
los fondos documentales de la Alta Comisaría de España en Marruecos, dichos expedientes venían referenciados en el sistema como: "Correspondencia de españolas con marroquíes". Este conjunto de expedientes resultan de gran interés, sobre todo, las cartas personales interceptadas por las autoridades españolas que se guardaban como prueba. A raíz del estudio de la documentación se cambia el título por otro más apropiado: "Expedientes de correspondencia interceptada entre españolas y marroquíes".

En este apartado se realiza un análisis diplomático de esta documentación y se recoge el procedimiento archivístico realizado al fichero con la finalidad de devolverle su función originaria, referenciar los expedientes informativos y facilitar su acceso a los mismos.

\subsection{EL FICHERO}

Antes de comenzar con el análisis del fichero, se realizó un trabajo previo de organización y clasificación, debido a que las fichas se encontraban desorganizadas en el interior de una caja del archivo, haciendo inservible el

\footnotetext{
${ }^{2}$ Ficheros de África sin identificar. Fichero de África $\mathrm{n}^{\mathrm{o}} 15$, Caja $1^{\mathrm{a}}$.

${ }^{3}$ En concreto la documentación se ubica en la intranet de PARES: INTRAPARES, por ello, su acceso en la actualidad sólo se puede realizar a través del personal de sala del AGA.
} 
fichero desde el punto de vista referencial. Dado que su organización originaria se había roto y con ella el principio archivístico de orden natural, decidimos organizar las fichas por el número de orden de expediente que contenían y no alfabéticamente por el nombre de las personas a las que se les había abierto el expediente, como probablemente se encontraban originariamente en las oficinas de la Delegación de Asuntos Indígenas ${ }^{4}$. Retomar su ordenación originaria era muy complejo pues las fichas no siguen una pauta a la hora de poner el nombre a quien se refieren, esto es, a veces aparece el nombre de la mujer, otras del varón, unas veces el nombre está completo y otras tan solo aparece el nombre de pila. Por otro lado, la ordenación numérica era más adecuada porque nos facilita la recuperación del expediente al que referencia las fichas, pues los expedientes están ordenados por número y no por orden alfabético. Una vez organizado el fichero se ha procedido a su digitalización con un Scanner I1220 de Kodak, escáner especial para fichas, con la finalidad de subirlo en formato PDF al sistema informático de instrumentos de descripción del Archivo General de la Administración, dando la posibilidad de acceder al mismo en la sala de investigadores. Por otro lado, se ha guardado otra copia de seguridad (master) en 300 de resolución, y formato TIFF para su conservación permanente. Tras su ordenación se compararon las fichas con los expedientes, dando de resultas, que muchos de ellos no se encontraban referenciados en las fichas, probablemente extraviadas, por lo que se ha realizado una relación de los expedientes sin ficha para incluirlos al final del fichero y complementar así las referencias que nos aporta.

Los ficheros de información generados por el Delegación de Asuntos Indígenas constituyen un complejo de información de carácter extraordinario, que supera en cierto modo, en su ámbito manual e histórico a cualquier sistema de información generado por ordenador. Desde el punto de vista diplomático podemos hablar de diversas tipologías de fichas dentro de este fichero:

\subsubsection{FICHA ÍNDICE}

Las fichas de índice se han ordenado originariamente por el alfabeto, pues estas vienen encabezadas por el nombre de pila o apodo de las mujeres y constituyen una lista referencial ordenada por dichos nombres, que remiten además a su número de expediente.

\footnotetext{
${ }^{4}$ Probablemente en su origen estuviesen ordenadas por orden alfabético, pues hay un par de fichas con los nombres personales en guías metálicas.
} 
Figura 1. Ficha índice

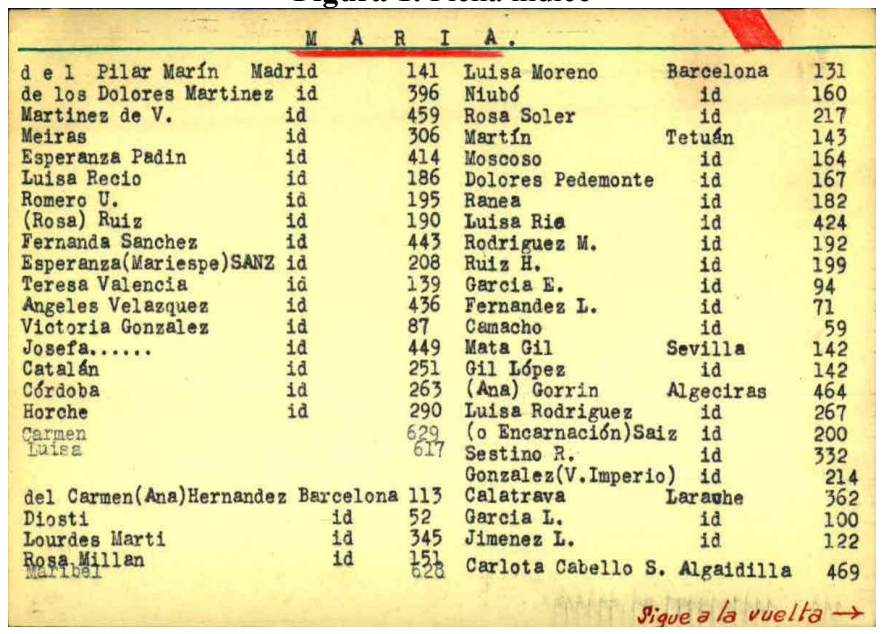

Este tipo de ficha tiene la estructura de un índice, la información se presenta en forma de listados de nombres personales, lugares y números de orden de expediente, que se iban incluyendo, quizás por orden de apertura del expediente, puesto que no reflejan un orden determinado. La ficha lleva marcado en rojo en la parte central superior el nombre de pila al que se refiere y en la parte inferior consta de dos columnas en las que se indican los apellidos de las mujeres con ese nombre, su origen (desde donde escribe/donde vive) y el número de expediente. Nos llama la atención que estas fichas poseen una franja de color (en este caso roja) en la parte superior derecha, esta franja, en diversos colores aparece en algunos informes contenidos en los expedientes informativos de la Delegación de Asuntos Indígenas. Este distintivo que aparece a menudo, se empleaba para la señalización, para facilitar la localización de la ficha, o bien para señalar su relevancia.

\subsubsection{FICHA DE INFORMACIÓN Y REFERENCIAL}

Figura 2. Ficha de información y referencial

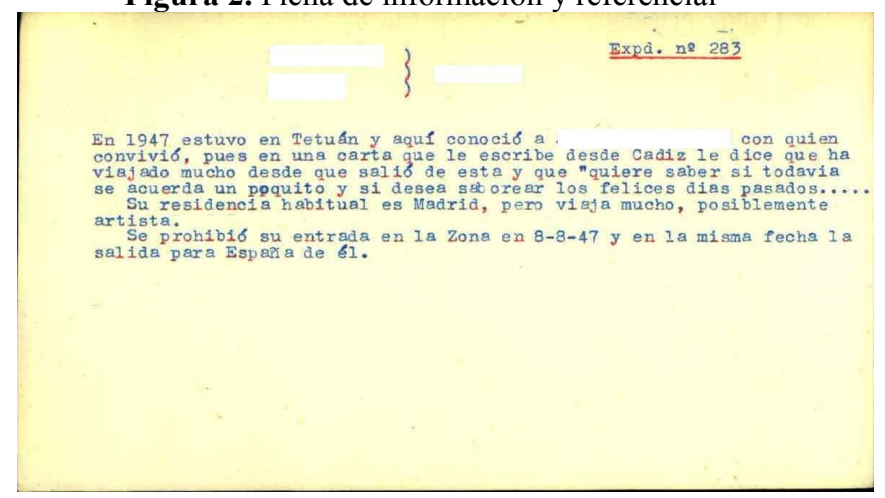


Este tipo de ficha es referencial porque nos remite a un expediente, este dato viene indicado en la parte superior derecha con: "Expd. $n^{\circ}$...". Pero no sólo es referencial, sino que también nos aporta información. En la parte superior central viene indicado el nombre y los apellidos (en este caso de la mujer, aunque en ocasiones aparece también el del hombre). En el caso de esta ficha, justo debajo se indica la dirección postal de la persona a la que se le ha abierto expediente (dato que se extrae de las cartas interceptadas). A continuación se aportan los datos recogidos de la correspondencia interceptada y de los documentos que se obtienen tras la investigación de la persona., por ello, se suele indicar a quien escribe, lugar de origen de la persona con la que se cartea, que relación mantiene con él/ella y datos de carácter personal. También se indica si tiene prohibida la entrada a la zona. Por último en la parte inferior de la ficha se indica el nombre de la persona a quien se refiere, primero apellidos y a continuación el nombre entre paréntesis.

En algunas ocasiones se hacen anotaciones a mano, bien para hacer alguna corrección, destacar información subrayándola, o bien para añadir más datos.

Estas fichas son importantes porque resumen los expedientes y las comunicaciones interceptadas, incluyendo juicios de valor del funcionario que tramita el expediente.

\subsubsection{FICHA CRUZADA}

Figura 3. Ficha cruzada

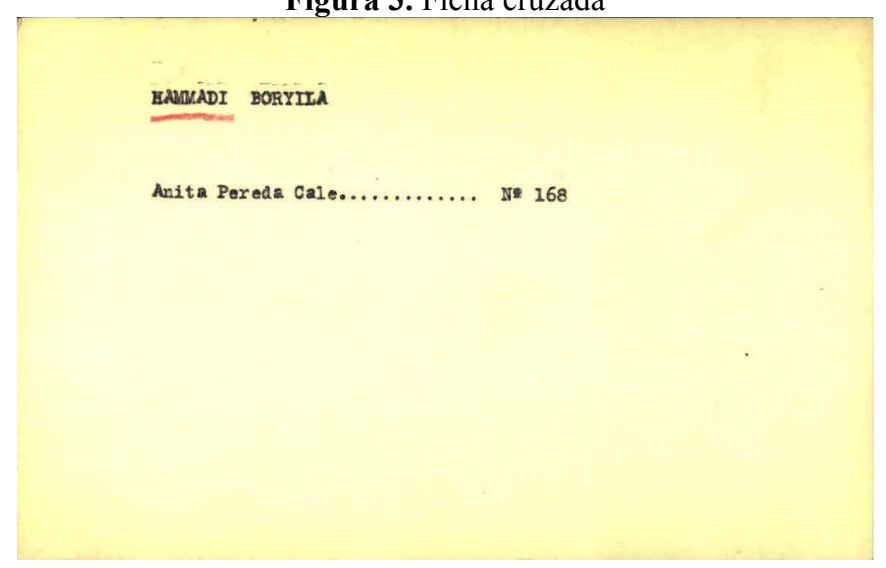

Este tipo de ficha no nos aporta información personal, los datos que podemos encontrar son referencias cruzadas, esto es, nos relaciona los nombres de las dos personas que mantienen una relación, a quienes se les intercepta la correspondencia. En la parte superior viene indicado el nombre completo del varón y se nos referencia con una mujer al lado (con la que supuestamente está relacionada), y nos remite al número de expediente que tiene abierto. La llamamos 
fichas de información cruzada porque no es la ficha principal de información o referencial, se emplea para derivar a otras fichas o expedientes en los que encontraremos la información personal de los sujetos a quien se refiere.

\subsubsection{FICHAS DE INFORMACION POR ASUNTOS: CURIOSIDADES Y DOCTRINA}

Figura 4. Ficha de información por asuntos: Curiosidades

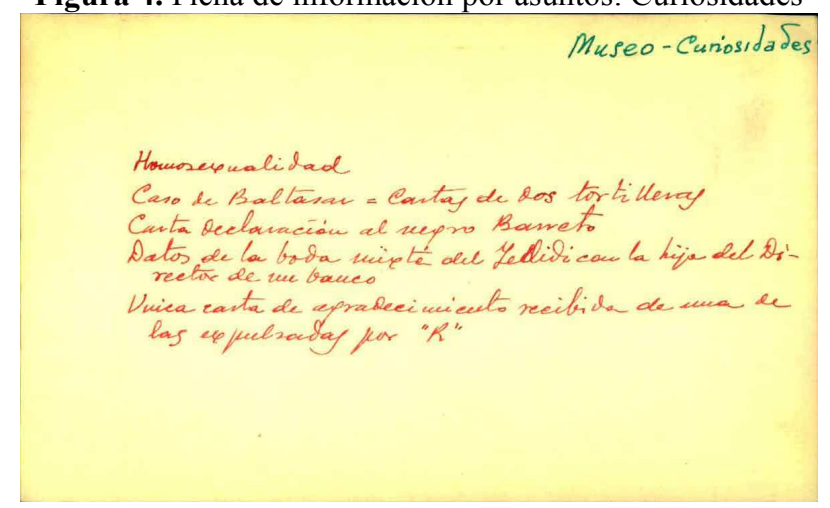

Figura 5. Ficha de información por asuntos: Doctrina

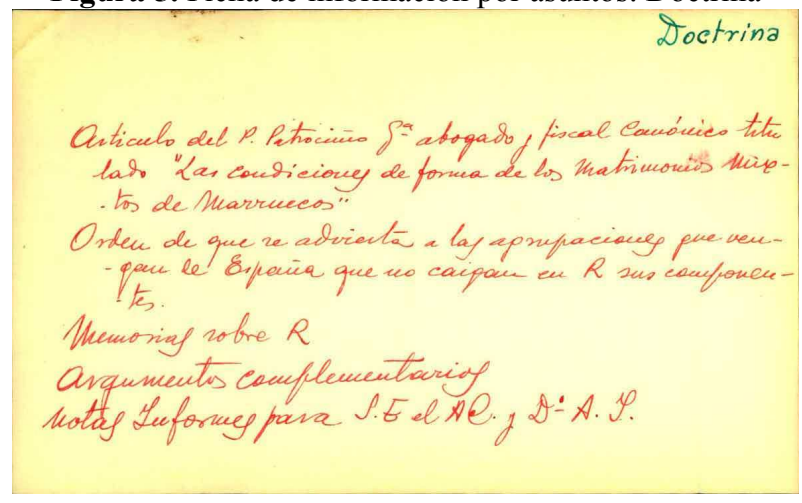

Estas fichas (figuras 4 y 5) hacen referencia a documentos importantes para entender el procedimiento que se seguía a la hora de conformar los expedientes y perseguir la homosexualidad y los matrimonios mixtos. Estos documentos a los que se refieren no son expedientes pero forman parte de la documentación adjunta. Son valiosos pues nos ayudan a entender los criterios que seguían para la recopilación de información, es decir, tanto la legislación como la doctrina en la que se basaba la persecución a sus protagonistas. 


\subsubsection{FICHA DE EQUIVALENCIA DE NOMBRES}

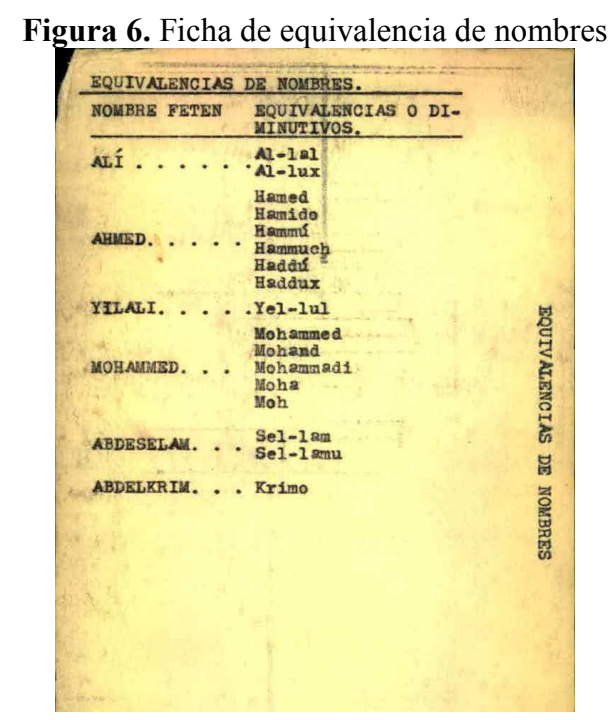

Este tipo de ficha hace referencia a la equivalencia de nombre marroquíes, hemos observado que muchas veces el mismo nombre viene escrito de varias formas diferentes, cuando se refiere a la misma persona. Un mismo expediente puede estar formado por documentos en los cuales el nombre se escribe de diferentes formas pero se trata del mismo individuo.

\subsection{EXPEDIENTES INFORMATIVOS}

Los expedientes personales de comunicaciones interceptadas de la Delegación de Asuntos Indígenas, que aparecían en el sistema informático como "Correspondencia de españolas con marroquíes", son expedientes que no responden a un procedimiento administrativo reglado, es decir, normalizado a través de la legislación. Esto se debe, fundamentalmente, a su carácter informativo, lo que los aproxima más a la tradición anglosajona de elaboración de expedientes por asuntos, que a la tradición basada en el trámite administrativo reglado. A pesar de no estar elaborados por un procedimiento legislado, si responden a un procedimiento de carácter no reglado y por tanto presentan una uniformidad en su formación, siendo parte de un proceso mayor de información, conformado por un conjunto más amplio de documentos, que tenía por objeto hacer llegar a todas las autoridades los acontecimientos más importantes del Protectorado, como hemos señalado anteriormente. 


\subsubsection{CARACTERES EXTERNOS}

El soporte en el que se encuentran los expedientes personales es el papel. Observamos el uso de diferentes tipos de papel en los documentos conservados dentro de los expedientes, según la tradición documental: copia, original,...y la calidad, España vivió una época de austeridad durante los primeros tiempos del Franquismo, lo que produjo escasez de papel, el mercado no se podía autoabastecer a pesar de la autarquía económica y hubo que hacer importaciones de tal material. La escasez de papel se refleja incluso en su reutilización con la finalidad de aprovechar los papeles de los documentos que ya no eran válidos. Este hecho se puede observar en la reutilización de carpetillas impresas, pero también en algunos casos en la propia documentación que forma los expedientes e incluso en las fichas. Según la tipología documental, también varía la calidad del papel.

Con respecto al tipo de escritura nos encontramos con documentos impresos como son las carpetillas que sirven para guardar la unidad documental compuesta que forma el expediente, sobre las que se plasmaban los descriptores del contenido del expediente por escritura manual o mecanográfica, No sólo se realizaban impresos para las carpetillas, también la DAI generaba sus propios expedientes $\mathrm{u}$ oficios impresos, con su membrete y sus datos más importantes, así como las propias oficinas de las intervenciones. Encontramos otros documentos impresos, que se completaban a mano como son los telegramas u otro tipo de formularios.

Los documentos del Servicio de Información de la DAI presentan marcas oblicuas, que nos recuerdan a las marcas encontradas en las fichas de sus ficheros, consistentes en una línea de color, observamos que se usan diferentes colores, quizás marcando la importancia o categorizando la información. Dichas marcas se encuentran en el margen superior derecho del documento, dicho posicionamiento permitiría rápidamente localizar los documentos dentro de un expediente.

Una de las tipologías más interesantes que nos encontramos en estos expedientes, son las cartas personales intervenidas por las autoridades españolas, que serían los documentos anexos que se presentan como testimonio de la conducta "amoral" de las personas fichadas. El soporte de estas cartas es de lo más variopinto, encontramos cartas escritas en papel de carta, en hojas de libretas,.... Pero siempre son documentos manuscritos con sus propias señas de identidad. En algunos casos se conservan los sobres de estas cartas, aunque los sellos aparecen, en ocasiones, recortados, suponemos que por un interés de colección o reaprovechamiento de los funcionarios por el que pasaron dichas cartas, es curioso porque hay sobres a los que les falta el sello pero conservan el franqueo. Con la correspondencia personal aparecen también fotografías que irían incluidas en las cartas intervenidas, así como giros de escala, telegramas, y hojas de interceptación de llamadas entre las personas vigiladas.

Como hemos indicado, la Delegación de Asuntos Indígenas conserva los documentos en carpetillas que conforman el expediente, estás carpetillas siempre 
indican los mismos títulos o "Personal Europeo" o "Personal Indígena", estos títulos muestran una primera clasificación general básica de la documentación del Archivo General del Protectorado. Estos títulos suelen venir impresos y se deja un espacio destinado para rellenar con el nombre, el asunto y el número de expediente, $\mathrm{u}$ otros datos, que se realizaban con escritura mecanográfica o manual.

A diferencia de otros expedientes de la Delegación de Asuntos Indígenas vienen guardados individualmente en sobres que en algunos casos llevan anotaciones personales. El hecho de guardarlos en sobres, nos lleva a plantearnos si se trata de darles un carácter más privado, o si se les daba una mayor importancia que a otros expedientes a la hora de su conservación.

Los documentos oficiales que conforman el expediente suelen contener diversas tipologías de sellado (membrete, matasellos,...), dependiendo del trámite de la documentación. Al ser sellado por los organismos por donde pasa dicha documentación, nos permite conocer un trámite documental que no viene regulado de manera expresa en ninguna norma, ya que hablamos de expedientes documentales no reglados, que incluso vienen desordenados internamente. Es importante tener en cuenta los sellos pues nos dan múltiples informaciones sobre el trámite del expediente, como puede ser quién crea el documento, cuándo y dónde. Además de los sellos identificativos y de validación, encontramos sellos de información como el que indica si un documento es "secreto" o "reservado" que nos muestran el carácter de esta información.

A parte de los documentos oficiales que conforman el expediente y las cartas encontramos también en algunas fichas de cartón mecanografiadas y notas no oficiales.

En cuanto al estado de conservación de la documentación, en general, es bastante buena, aunque observamos bastantes indicios de "foxing" en algunos documentos, este signo de deterioro documental consiste en la aparición de manchas de color marrón en el papel. Probablemente su origen se encuentre en la calidad de los materiales, fundamentalmente por el uso de sustancias oxidantes en la fabricación de los papeles, que corroboraría la escasez de este material en la posguerra española.

\subsubsection{TIPOLOGÍA Y ESTRUCTURA DIPLOMÁTICA}

En este apartado analizamos las tipologías documentales así como la estructura interna de algunos de los documentos que forman parte de los expedientes personales.

1. Tipología de expediente: Expedientes personales de correspondencia interceptada entre españolas y marroquíes.

Relación de tipologías de documentos:

- Documentos de la Delegación de Asuntos Indígenas (Oficios, Informes, Notas Interiores,...).

- Documentos de las Intervenciones (Oficios, Informes, Notas Interiores,...). 
- Documentos interceptados (Telegramas, Giros postales, Cartas, Fotografías, Sobres de las cartas, Fichas de conversaciones)

- Fichas de cartón y anotaciones no oficiales.

\subsubsection{CARPETILLA}

Las carpetillas sirven para mantener unidos los documentos que conforman el expediente, evitando la mezcla con otros documentos no relacionados. Es reseñable que en estos documentos existe además de la carpetilla, otros elementos protectores, como son unos sobres en los que se encuentran introducidos los expedientes y en los que se incluye el nombre del expedientado y algunas anotaciones sobre el expediente. Dicho celo de protección es posible que sea debido a su carácter reservado.

Dichas carpetillas están estandarizadas. Todas incluyen, en primer lugar, el organismo productor, en este caso la Delegación de Asuntos Indígenas. También indican la clasificación de los expedientes en la oficina, en este caso "Personal Europeo". Se queda un espacio para el nombre de la persona a la que se le abre el expediente. Y por último, se destinan un par de líneas para referenciar la información y hacer anotaciones sobre el expediente o sobre la persona al que este se refiere.

Figura 7. Carpetilla

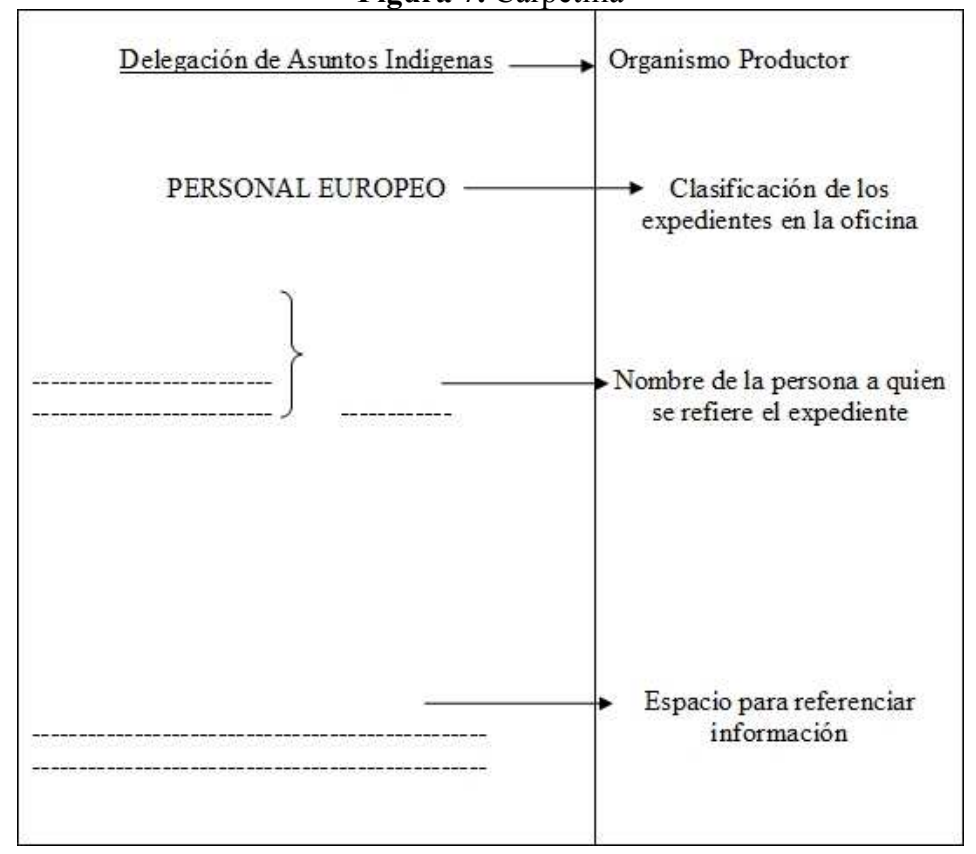




\subsubsection{DOCUMENTOS DE LA DELEGACIÓN DE ASUNTOS INDÍGENAS}

Uno de los documentos que conforman el expediente sería el que proviene de la Delegación de Asuntos Indígenas. Este documento posee en la parte superior izquierda el membrete que nos indica la dirección del autor del documento. En la parte superior derecha se indica la numeración del documento. A continuación, en un nivel inferior se indicaría la data tópica y crónica, es decir la fecha y el lugar donde se crea el documento. A continuación, encontramos un espacio destinado al asunto, este daría título al documento. Después hay un espacio destinado al cuerpo del texto, a la exposición de la información y por último encontramos un sello estampado que sirve como validación de la documentación y el destinatario que sería a quien va destinado el documento, esto se indica en una línea al final del documento como viene señalado en el ejemplo. El tipo de información que nos aporta la documentación es siempre igual ya que estaba estipulada en las bases de las comunicaciones internas. Hemos encontrado fuentes documentales que hacen referencia al procedimiento de elaboración de los documentos, concretamente como tenían que redactarse los documentos dependiendo de su tipología y como tenía que indicarse claramente el destinatario a quien iban dirigidos para evitar confusiones.

Figura 8. Documentos de la delegación de asuntos indígenas. Documento tipo extraído del expediente número 2. Signatura: A.G.A. 81/2568

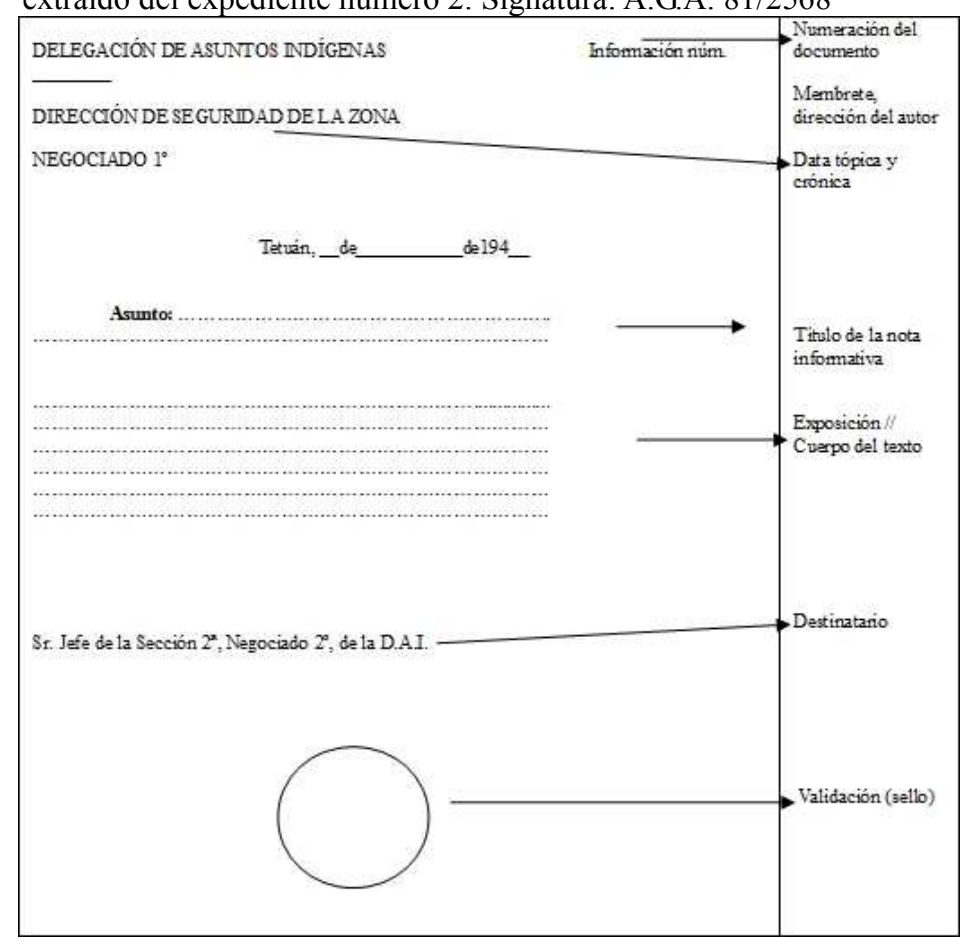




\subsubsection{DOCUMENTOS DE LAS INTERVENCIONES}

Otra de las tipologías de documentos que conforman los expedientes son los generados por las Intervenciones Regionales. En la parte superior izquierda se encuentra el membrete que nos indica la institución productora del documento, en este caso, la Intervención Territorial de Chauen, también se indica el departamento al que pertenece, el de Información. En la parte superior derecha se indica el número de documento. Se indica también la data tópica y crónica de documento. A continuación, distinguimos cuatro partes bien diferenciadas: Asunto, que sería el título de la nota, en este caso es donde se refiere el nombre de la persona sobre la que versa el expediente en el que viene incluido este documento; Referencia, donde se indica otros documentos que tienen que ver con este; Cuerpo de la noticia o exposición, donde se narran los hechos; y por último el Destinatario, que será quien reciba la nota informativa. Como en el documento anterior, este, lleva un sello como validación. Observamos que este documento en la parte superior derecha presenta una franja de color, en este caso es verde. Hemos observado que hay varios tipos de documentación que poseen franjas de color en la parte superior derecha. Esto debe ser por un criterio de ordenación y búsqueda referenciada mediante el color. También es reseñable que tiene un sello de SECRETO y una marca "R" que se refiere al carácter reservado y secreto de esta documentación.

Figura 9. Documentos de las intervenciones. Documento tipo extraído del expediente número 2. Signatura: A.G.A. $81 / 2568$

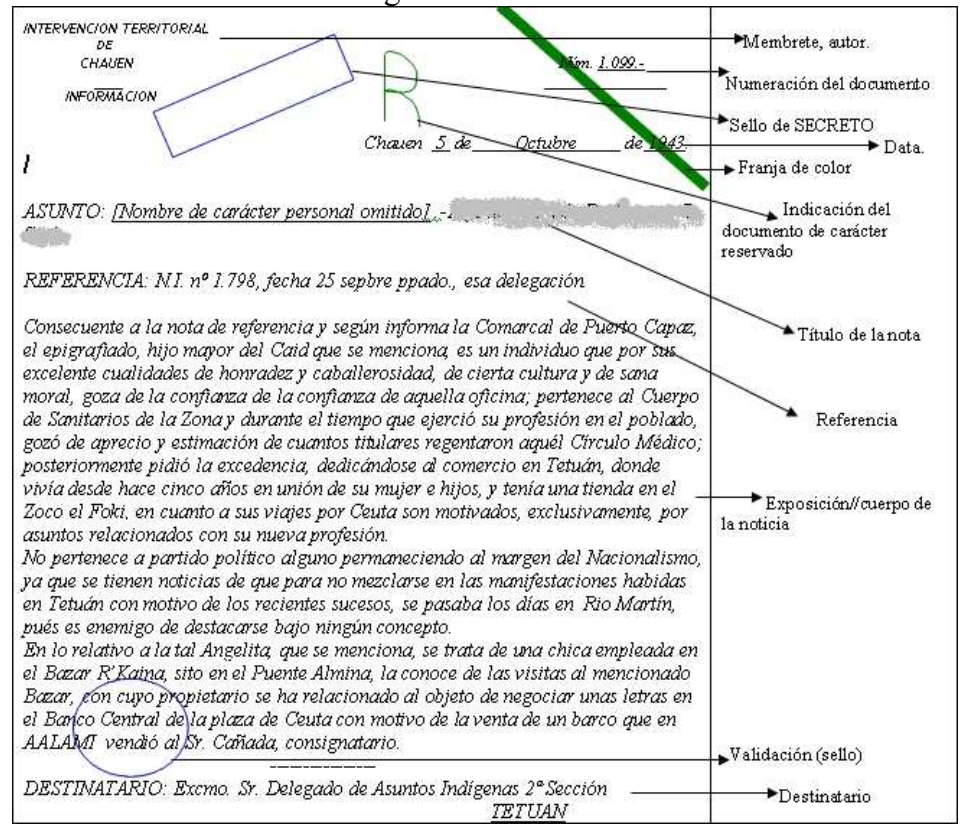




\subsubsection{FORMULARIO DE CONVERSACIONES}

Este formulario se empleaba para recoger las conversaciones telefónicas interceptadas, no sólo se captaban materiales escritos, sino que también conversaciones telefónicas. Para ello tenían unos documentos normalizados para recoger esta tipología de información. Este es un ejemplo de este tipo de documento o ficha de conversación.

Figura 10. Formulario de conversaciones. Documento ejemplo extraído del expediente número 6. Signatura: A.G.A. $81 / 2568$

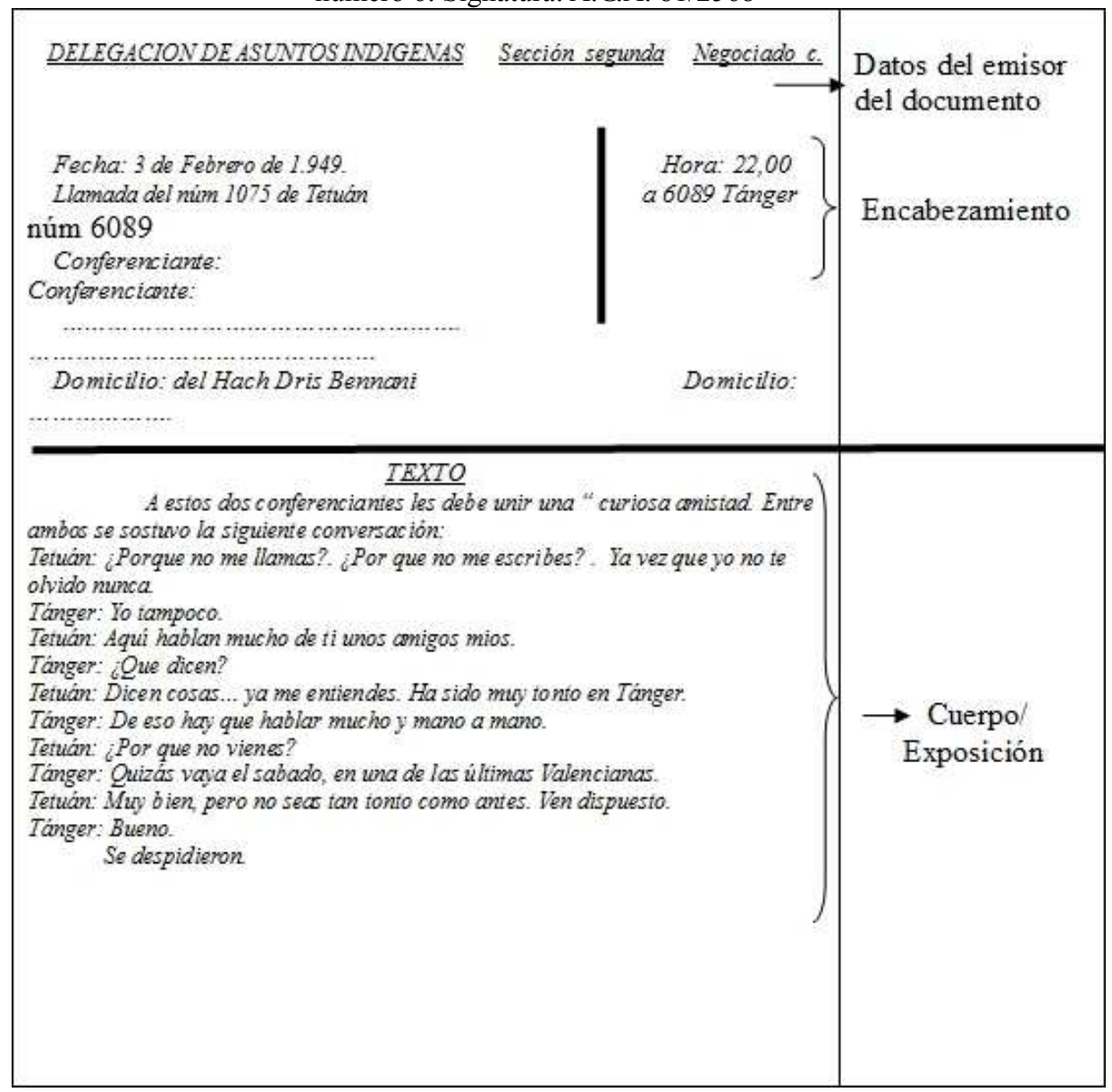




\subsubsection{CARTAS}

Esta carta forma parte de la caja AGA,81,2568, es un documento anexo al expediente número 38 de la caja con signatura AGA,81,2568. La hemos escogido a modo de ejemplo, la estructura diplomática de las cartas varía con respecto al resto de los documentos, pues se tratan de documentos personales, en los que existe una mayor libertad de creación frente a los documentos oficiales que deben seguir una estructura preestablecida. Aún así las cartas por lo general presentan una estructura común. Al comienzo aparece el lugar y fecha en la que han sido escritas, es decir, la data crónica y tópica. Le sigue el encabezamiento, en esta parte suelen aparecer una clase de fórmulas utilizadas al escribir correspondencia que varían según la época, en esta, en concreto, aparece la fórmula en el encabezamiento "querido....", u otras fórmulas propias de cartas más personales como: "Tuya siempre".

Las cartas personales encontradas entre los expedientes son los documentos más interesantes, porque muestran el grado de alfabetización de las personas durante la posguerra española, tal y como sucede en este ejemplo, donde se aprecia la ausencia de una gramática y ortografía correcta. Estas cartas muestran como mujeres de diversas clases sociales mantenían relaciones con los marroquíes.

Figura 11. Cartas. Documento como ejemplo anexo del expediente número 38.

Signatura A.G.A. 81/2568

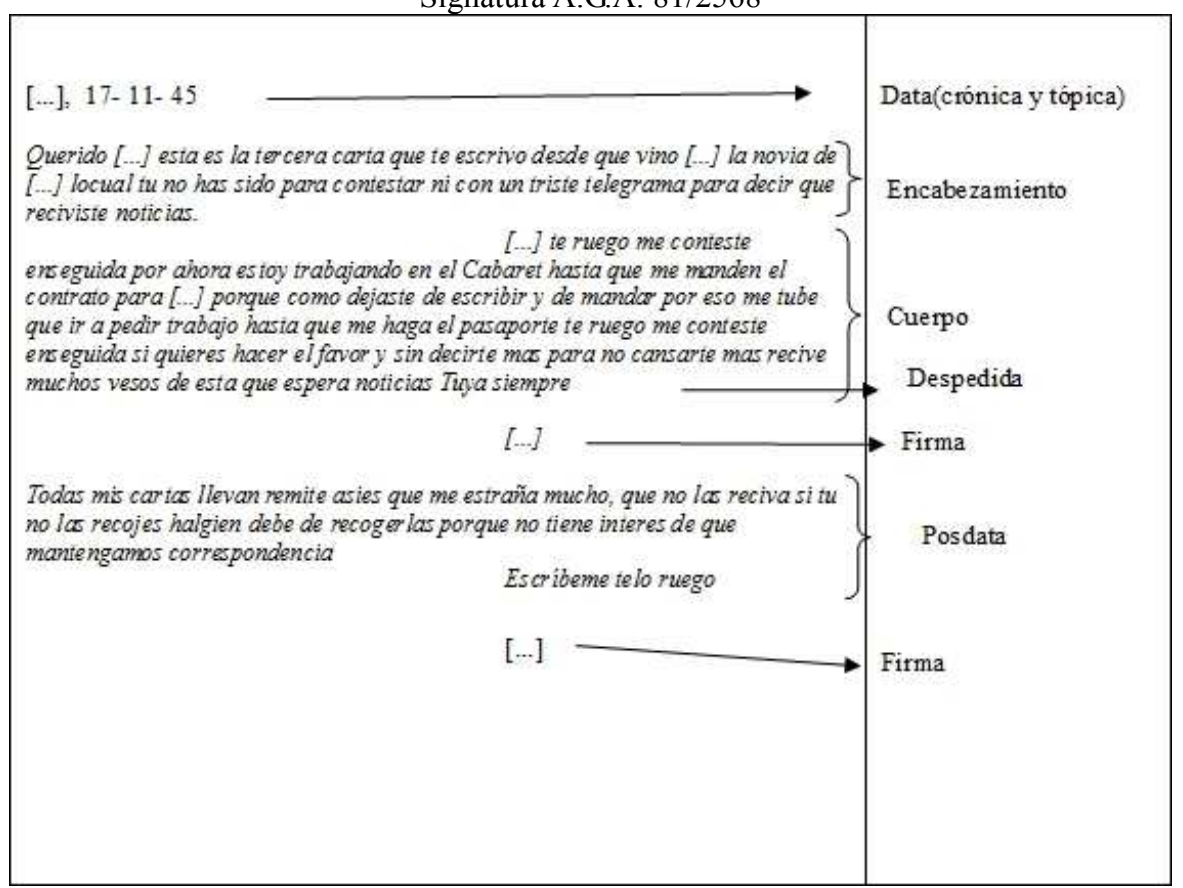




\section{EL CONTENIDO DE LAS COMUNICACIÓN INTERCEPTADAS}

Las correspondencia interceptada que se contiene en los expedientes informativos, son documentos históricos y sociológicos de gran transcendencia, porque nos acercan a las relaciones prohibidas entre españolas y marroquíes durante la época de la posguerra española.

En los informes se recoge un dato que nos crea grandes dudas acerca de su veracidad, se indica un alto porcentaje de mujeres perseguidas ejerciendo la prostitución o trabajando como artistas de cabaret. Estos datos resultan más propios de juicios morales a priori realizados por funcionarios alejados de las personas que juzgaban, que de hechos derivados de una realidad contrastable.

$\mathrm{Si}$ leemos a fondo las cartas, podemos ver que se trataba de mujeres enamoradas y luchadoras que trataban en todo momento defender unos sentimientos que nadie debería juzgar, permitiéndoles entregar su corazón con plena libertad.

El ejercicio de esta libertad en una sociedad controladora resultó una tarea ardua, sin embargo, en algunos casos la lucha mereció la pena y pudieron cumplir su deseo de amar sin ataduras.

El contenido de estas "cartas de amor" resulta muy variado ya que nos encontramos con un gran número de cartas interceptadas. En algunos casos sus protagonistas consiguen pasar la censura amorosa, en cambio otras, recogen un final desgraciado a esta aventura interétnica.

Aunque la temática central de las cartas es amorosa, también sus protagonistas narran las experiencias vividas o su rutina diaria.

\subsection{EL CONTROL DE LA MORALIDAD DURANTE LA POSGUERRA ESPAÑOLA}

Como indica Josep Lluís Mateo Dieste en su artículo Amores prohibidos. Fronteras sexuales y uniones mixtas en el Marruecos colonial: "La mujer española debía ser protegida ante la amenaza del "moro violador"».

Tras haber conocido más a fondo las historias de los documentos analizados debemos hacernos una serie de preguntas ¿Quiénes somos nosotros para juzgarles? Del mismo modo que ¿Quién era la Delegación de Asuntos Indígenas para interceptar esta correspondencia?

En nuestra sociedad, parece algo evidente, nadie debe de juzgar la moral de nadie, sin embargo, en la época en la que se desarrollaron estos acontecimientos, juzgar la moral de las relaciones humanas era algo habitual e incluso penable. Uno de los objetivos del estado de Franco era conservar la pureza de una raza, la española, que contradictoriamente había sido el resultado de la unión de varias culturas: la judía, la cristiana y la musulmana. 
Desde la Edad Moderna se ha identificado a la población africana con la irracionalidad y la naturaleza, considerando incluso al profeta Muhammad como promiscuo y homosexual.

Sin embargo, en España durante la II República los matrimonios mixtos se legalizaron pero en la época franquista se declararon nulos los matrimonios musulmanes de las mujeres españolas, salvo que estas presentaran una prueba legal de su condición "no católica", o una declaración de no haber sido bautizada. Los matrimonios mixtos se consideraron un peligro para la patria y el orden moral.

La existencia de amistades, noviazgos, "amancebamientos" y matrimonios mixtos provocó que las autoridades se pusieran en alerta por distintas razones, como, por ejemplo: Mezclarse con un inferior era inapropiado y además podía generar en familiaridades con el colonizado.

El sistema de represión se desarrolló tras la Guerra Civil y como consecuencia del desplazamiento de entre 60.000 y 100.000 marroquíes a España. En 1936, la Delegación de Asuntos Indígenas estableció un sistema de censura postal, telegráfica y telefónica que tenía como objetivo vigilar las comunicaciones entre Tetuán y la Península. Algunas medidas que se aplicaron en Marruecos a principios de 1940 consistían en interceptar la correspondencia de llegada, prohibir la entrada a la Zona de las mujeres identificadas o denegar los salvoconductos de los marroquíes para ir a España.

La Delegación de Asuntos Indígenas consideraba que el matrimonio entre una española con un marroquí era un desprestigio de "raza" para la nación dominante y protectora.

Las relaciones mixtas más frecuentes eran las que se daban entre marroquíes y mujeres españolas, aunque en algunas ocasiones hemos podido encontrar informes que hacen referencia a hombres judíos e indios

En su mayoría, los hombres tenían un origen modesto como, por ejemplo, funcionarios, chóferes, espías, comerciantes y hombres de negocios. El origen de las mujeres también solía ser humilde, en los informes encontramos referencias a tanguistas, prostitutas y artistas de cabaret.

En una caja hemos podido encontrar un informe que hace referencia a la moralidad de las relaciones mixtas y en el que se intenta justificar porqué estas relaciones son perjudiciales.

Estos son algunos fragmentos que hemos seleccionado ya que nos parecen bastante representativos: "Nuestro prestigio de Nación protectora resulta gravemente dañado con estas relaciones; los comentarios de musulmanes, a este respecto son dolorosos para nuestra dignidad y la Raza no gana precisamente con estos contactos por la degeneración, perversión sexual y lamentablemente estado sanitario de los marroquies (...)”.

Como podemos observar en este párrafo hay un racismo que provoca que se destaquen cosas negativas de los marroquíes que probablemente no estarían contrastadas. 
En este párrafo se habla de la censura ejercida como posible solución para destruir las relaciones mixtas: "Esta Delegación viene ejerciendo desde algún tiempo la censura y detención de la correspondencia entre musulmanes y españolas, como medio de conocer los términos y alcance del problema, y como procedimiento de atajarlo o combatirlo (...)".

En otro párrafo se señala: "Hay en estos expedientes repetidos casos de apostasía, matrimonios clandestinos celebrados por el rito coránico, estupros, violaciones, concubinatos, corrupciones de menores, seducciones, promesas de matrimonio que no se cumplen (y es preferible que no se cumplan), etc, y como consecuencia inherente a esta serie de calamidades, muchos hogares españoles deshonrados o deshechos, mujeres ultrajadas, perdidas y engañadas, hijos desamparados y tarados fisica y moralmente y siempre; como denominador común a todas estas vergüenzas, el escarnio de nuestra Religión y el daño irreparable a nuestro prestigio nacional."

Los censores además de impedir que las relaciones pudieran sobrevivir juzgaban la moral de otros, cuando probablemente su moral también era dudosa.

Por otra parte, debemos de tener en cuenta que no se puede generalizar y si un marroquí había actuado mal en alguna ocasión no todos los demás eran así. Es probable que muchos hombres españoles también actuaran mal con sus esposas pero eso nadie lo juzgaba porque eran de la misma nacionalidad.

"La censura y detención de la correspondencia, puesta en práctica por la Delegación de Asuntos Indígenas, ha dado ya resultados satisfactorios; gracias a ella se han descubierto muchos casos, se han dificultado nuevas relaciones, se han cortado o entorpecido otras antiguas y se ha evitado la consumación de hechos que, sin esta medida, hubieran resultado irreparables (...).

Otras medidas que pueden adoptarse por esta Delegación- tales como la prohibición de salida de musulmanes del Protectorado y entrada de españolas en la zona.- (...)".

Por otro lado encontramos un informe referido a los marroquíes que estudiaban en Granada. Eran controlados puesto desde la Alta Comisaría no se deseaba que mantuvieran relaciones con mujeres españolas.

Este es un fragmento de uno de los informes:

"Mientras están en la Casa de Marruecos o en los Centros docentes donde cursan, sabemos perfectamente lo que hacen; pero en las horas de asueto (que no son más de dos al día) no los podemos vigilar directamente y por esto, desde el año pasado y a raiz del incidente Bugaba encargué a un Agente de la Jefatura superior que vigilase discretamente a los chicos (...)" 
Este párrafo es un claro ejemplo de la durísima represión que sufrían los marroquíes. En esta situación era prácticamente imposible poder tener una relación con una mujer española. Sin embargo, el amor llega sin avisar y no entiende de colores o nacionalidades.

\subsection{TRANSCRIPCIÓN DE ALGUNAS COMUNICACIONES}

Hemos decidido seleccionar y transcribir una serie de cartas para mostrar de manera más tangible el contenido de estos documentos que narran auténticas historias vitales.

\section{Epístola I: “Contra viento y marea”}

Esta pareja $^{5}$ tuvo que luchar para que su amor sobreviviera. Como no estaban casados ella tenía prohibida la entrada en la zona, para que pudieran autorizarla a volver tenía que casarse con su pareja. Aunque fue difícil, ya que tuvieron que luchar contra viento y marea para poder estar juntos, finalmente pudieron contraer matrimonio.

Esta es una de las cartas que escribe la mujer:

"'Querido [...], recibi tus dos telegramas, espero que al recibo de esta se encuentren Vds. Todos bien yo impaciente y azuqueada en espera de mejor suerte, con esta fecha os escribe [...] a [...] y a ti, pues yo quisiera que [...] o mi hermana me sacaran la partida de Bautismo mía, otra nueva con fecha corriente, y me la mandarán si en nuestro asunto está libre la competencia de la Alta Comisaría como no puedo yo marchar a esa, que es lo que pasa ahora, a ver si la persona que nos ha denunciado viendo que hemos triunfados, pues sigue haciendo la faena,

Ten cuidado pues puede ser que te sigan los pasos y lo que tu arregle te lo desarreglen, por otro. Ve por casa de mi hermana y procura ver a Rosa que no escribe para saber de ellos y sin contarte mas Vds. Reciben un fuerte apreton de brazos para tu madre y tu hermana y hasta la tuya que sea pronto."

Este es un informe en el que podemos conocer más a fondo la historia de nuestros protagonistas:

"Con esta fecha se ha expedido salvoconducto por este Centro a favor de la mencionada en el epigrafe, a fin de que pueda efectuar su entrada en esta

\footnotetext{
${ }^{5}$ Los nombres de las personas de las cartas se han omitido para preservar su intimidad, aunque el tiempo que ha transcurrido para su publicidad es suficiente. Se han sustituido los nombres por [...]

${ }^{6}$ La carta está transcrita con la misma ortografía y gramática que una copia encontrada en el expediente $n^{\circ} 98$ Signatura: A.G.A 81/2569.
} 
Plaza para contraer matrimonio con el marroqui [...], y por haber quedado sin efecto la "expulsión de la Zona" de la citada Carmen, aprobada por el S.E. el Alto Comisario con fecha 5 de septiembre último, con la condición de que contraigan matrimonio a la mayor brevedad.

Lo que se participa a esa Sección para conocimiento y en relación con a nota indicada."

\section{Epístola II: “Contesta pronto"}

Hemos seleccionado esta carta, ya que nos llama mucho la atención su contenido por los fuertes sentimientos que muestra en su expresión la autora.

7 "VOI A CONTINUAR ESCRIVIENDOTE /PARA QUE ME DIGAS CUANTO TABACO LEAS MANDADO A/ ENRIQE PUES TAN NIEN PODIAS/ A BER MANDADO UNAS LETRAS/ POR QUE NOSOTRAS TODOES/ PREGUNTA PARA QE MED i [...] DI/GAN COSAS DE TI ¿NADIE ME DICE NADA. A SIES QEBEN/ ;MELAS CONTARAS TU TODAS LAS/ QE [...] QIERO SABER./ MARIA MEDICE QUE QUANDO BENGAS/ QE LE TRAIGAS UNA COSA/ ¿TU SABES LOQUEYOTEPIDO?/ QEMEMANDES ESA [...] FOTOFRAFIA QE ME DECIAS/ QEMEMANDARIAS PUES TEGO//GANAS DE [...] VERTE/ PUES PIENSAELO BIEN/ PUES SI TUBIENES TENLO POR/ SEGURO QETEBOLBERIAS A CASA/ ACONPAÑADO PUES SITUS/PADRES NOME PEGA NI A MI NI A TI/ SEGURO QE ME BOI CONTIGO/ SI NO TE AS CASADO CONTESTA PRONTO “” $\quad$ PRONTO

“”, PRONTO

Sin mas recive un fuerte/apreton de mano de esta tu amiga/ que mucho te quiere (BEN PRONTO NOTARDES) ”

Tras la lectura, podríamos deducir que la mujer que la escribe tiene unos sentimientos muy fuertes hacia su receptor. Sin embargo, en los informes realizados sobre estas dos personas se dice que nunca habían tenido una relación, aunque la persona a la que va dirigida la carta sí lo había intentado.

${ }^{7}$ Las cartas están transcritas con la misma ortografía y gramática que las originales. Expediente $n^{\circ}$ 97, Signatura: A.G.A 81,2569. 


\section{Epístola III: “Amarga traición”}

Esta historia nos muestra la decepción de la protagonista ya que considera que un marroquí ha tenido un mal comportamiento con ella. Hallamos estas palabras en una carta que escribe a su amigo.

Este es un fragmento de la carta:

8 "Estimado amigo [....]:

Unas letras para decirte que no puedes figurarte cuanto me extraña vuestro comportamiento, pues yo creo que quedamos en que nos veríamos en la estación todos y no comprendo porqué no cumplieron la palabra, en fin, comprendo que tendriais algún motivo para hacerlo así y no reconozco que después de todo, ni tú ni [...], tenéis obligación de nada conmigo, y de todas formas yo estoy muy agradecida a los dos y les doy mis sinceras gracias por todas las molestias que yo les haya causado, y les escribo para que vean que nunca me olvidaré de unos amigos que para mi fueron tan buenos y amables; en cambio no quiero acordarme de la conducta de [...], pues no encuentro palabra para calificarle, pues se ha portado como un embustero cobarde pues lo que ha hecho no tiene ningún hombre que por tal se tenga; dejarme sola en una situación tan apurada y casi sin recursos para nada; cuando tantas veces me habia prometido tantas cosas y decía que me quería tanto, no comprendo porqué mentía de esa manera, pues nadie le obligaba a ello, en fin, prefiero olvidarme de él pues no merece otra cosa y siento en el alma haberlo creído por un momento (...)".

Desconocemos cuál era la relación entre esta pareja ya que en el expediente sólo encontramos dos transcripciones de la carta y otro documento, pero no nos da ninguna pista de su situación.

\section{CONCLUSIONES}

Esta información, que hemos rescatado a través de su organización, nos revela testimonios que han permanecido ocultos en el tiempo, de mujeres cuyo único delito fue enamorarse de quien no les era permitido por el régimen y por ello recibieron un trato vejatorio.

La documentación aquí expuesta y de la que hemos partido para realizar este artículo está disponible para su consulta, tanto de investigadores como para afectados que deseen conocer las historias reales y la verdad sobre las relaciones que traspasaron fronteras. Esta documentación no sólo es importante por su

\footnotetext{
${ }^{8}$ La carta está transcrita con la misma ortografía y gramática que una copia encontrada en el expediente $n^{\circ} 86$, Signaturas: A.G.A 81,2569.
} 
contenido, también lo es por la diversidad de tipología documental que aglutina. En los expedientes a los que se refieren las fichas de las que partimos para llevar a cabo nuestro trabajo se mezclan desde documentos oficiales, así como notas internas, cartas originales que fueron interceptadas, incluso documentos normativos de porqué una mujer española no debía "bajar de categoría" manteniendo una relación amorosa con alguien que no fuese de su misma "raza, religión o condición" y de como se llevaban a cabo los seguimientos a individuos para conseguir y mantener los valores que el régimen había establecido.

Ésta documentación se puede consultar en el Archivo General de la Administración, en Alcalá de Henares. Queremos aprovechar para señalar, el papel de los archivos en la descripción y conservación de documentos, sin cuya labor no sería posible acceder a la información que custodian. También señalar que el fichero del que hemos partido está digitalizado en el repositorio institucional del Archivo General de la Administración facilitando así su difusión y consulta.

\section{REFERENCIAS BIBLIOGRÁFICAS}

MATEO DIESTE, Josep Lluis (2006). “Amores prohibidos. Fronteras sexuales y uniones mixtas en el Marruecos colonial", Ana Planet (ed.) Marruecos y España. Una vecindad en construcción, Madrid: Ediciones del Oriente y del Mediterráneo, pp. 128-159.

MATEO DIESTE, Josep Lluis (2003). «Pourquoi tu ne m'ecris plus...?» Les relations mixtes et les frontières sociales dans le protectorat espagnol au Maroc ». En : Hawwa. Journal of Women of the Middle East and the Islamic World, $\mathrm{n}^{\circ} 2$, vol. 1, pp. 241-268.

MORA VILLAREJO, Luisa (2012). El protectorado español en Marruecos a los 100 años de la firma del tratado: Fondos documentales en la Biblioteca Islámica. Madrid: Editorial Agencia Española de Cooperación Internacional para el Desarrollo. Ministerio de Asuntos Exteriores y de Cooperación.

NASEIRO RAMUDO, Ana (2012). Evolución histórica de la descripción archivística en España en la época contemporánea. Análisis de de la transformación de los instrumentos de control y descripción. Del catálogo manuscrito a los gestores Web de objetos digitales culturales. [Tesis Doctoral]. Universidad de la Coruña.

RIESCO TERRERO, Ángel (2000). Introducción a la paleografía y la diplomática general. Madrid: Editorial Síntesis.

TAMAYO, Alberto (1996). Archivística, diplomática y sigilografía. Madrid: Cátedra.

VILLANOVA VALERO, José Luis (2006). Los interventores. La piedra angular del protectorado español en Marruecos. Barcelona: Editorial Alboran bellaterra.

VILLANOVA VALERO, José Luis (2004). El protectorado de España en Marruecos. Organización política y territorial. Barcelona: Editorial Alboran bellaterra. 